\title{
Genetic variability in sugarcane (Saccharum spp. hybrid) genotypes through inter simple sequence repeats (ISSR) markers
}

\author{
Vivekanand P. Rao ${ }^{*}$, Sanjay Singh $^{1}$, R. Chaudhary ${ }^{1}$, M. K. Sharma ${ }^{1}$, R.S. Sengar ${ }^{1}$, Uma \\ M. Singh ${ }^{2}$ and Vinay Sharma ${ }^{3}$
}

${ }^{1}$ Department of Agriculture Biotechnology, College of Agriculture, Sardar Vallabhbhai Patel University of Agriculture \& Technology, Meerut- 250110 (U.P.), INDIA

${ }^{2}$ Department of Molecular Biology \& Genetic Engineering, G.B. Pant University of Agriculture and Technology, Pantnagar-263 145 (Uttarakhand), INDIA

${ }^{3}$ Department of Bioscience and Biotechnology, Banasthali University Banasthali- 304022 (Rajasthan), INDIA

*Corresponding author. E-mail: raovivekanand4@gmail.com

Received: November 26, 2015; Revised received: May 10, 2016; Accepted: July 28, 2016

\begin{abstract}
In the present study, 14 sugarcane (Saccharum spp. hybrid) genotypes were used for genomic diversity analysis based on nineteen inter simple sequence repeat (ISSR). These nineteen sets of ISSR markers generated a total of 164 discernible and reproducible bands including 109 polymorphic and 55 monomorphic bands. The unweighted pair group method with arithmetic average (UPGMA) analysis revealed three distinct clusters: I, II and III within the 14 genotypes. The polymorphic information content (PIC) value per locus ranged from 0.14 (UBC811) to 0.53 (ISSR1) locus with an average of 0.42 for all loci. The range of genetic distance or coefficient of similarity among sugarcane genotypes varied $0.14-0.78$. The analysis of these similarities matrix revealed that greater similarity between CoS03234 and CoSe1424 (0.78), and lowest similarity between CoS03234 and Co0118 (0.14). The knowledge gained in this study would be useful to future breeding programs for increasing genetic diversity of sugarcane varieties and cultivars to meet the increasing demand of sugarcane cultivation for sugar and bio energy uses.
\end{abstract}

Keywords: Genetic diversity, Inter simple sequence repeat (ISSR) marker, Unweighted pair group method with arithmetic average (UPGMA)

\section{INTRODUCTION}

Sugarcane (Saccharum spp. hybrid) is an important industrial crop for the tropical and subtropical region of the world. It is produced in more than 100 countries, with global production of 175.1 million tonnes of sugar. It accounts for about 80 percent and sugarbeet for about 20 percent of total sugar produced (FAOSTAT, 2015). Economically sugarcane is an important industrial raw material for sugar and allied industries producing alcohol, acetic acid, butanol, paper, plywood, industrial enzymes, animal feed and bioethanol as a biofuel alternative to petrol. Brazil is the largest sugarcane producer country, contributing with $40.4 \%$ of the world production (768 MT) followed by India 17.9\% (341.43 MT), (FAOSTAT, 2015).

The complexity and size of the sugarcane genome is a major limitation in genetic improvement. Genetic diversity can be estimated based on different methods, morphological traits, pedigree record and molecular markers. The use of molecular markers for evaluation of genetic diversity is receiving much more attention. Molecular marker is a potentially valuable tool for crop improvement. Molecular markers play a role to portray genetic variability in several crops. Now a day, fingerprinting system based on Inter simple sequence repeat (ISSR) analysis have been increasingly utilized for detecting polymorphism in those genera which has no prior sequence information. ISSR markers have several advantages over other polymorphism detection techniques including RFLP, AFLP and other markers. ISSR marker system is another newly developed method, which relies on one primer for PCR that anneals to an SSR region and amplifies region between inversely oriented adjacent SSRs (Pandey et al., 2012). ISSR assay can be undertaken for any species that contains a sufficient number and distribution of SSR motifs and has the advantage that genomic sequence data is not required. This technique amplifies large numbers of DNA fragments per reaction, representing multiple loci from across the genome; it is an ideal method for fingerprinting varieties. There have been substantial reports of genetic diversity analysis of different crops including sugarcane plants using molecular markers (Singh et al., 2010; Zhang et al., 2008; Tabasum et al., 2010; He et al., 2011; Rao et al., 2014) included ISSR in sugarcane (Costa et al., 2011; Kalwade et al., 2012; Devarumath et al., 2012). The present investigation was conducted to study the genetic variability in sugar- 
cane (Saccharum spp. hybrid) genotypes through inter simple sequence repeats (ISSR) markers.

\section{MATERIALS AND METHODS}

Pot experiment was laid out by planting 14 sugarcane genotypes (Table 1), based upon highly contrasting morphological feature obtained from gene pool of Sugarcane Breeding Institute, Regional Station, Karnal, Haryana, India. Fresh leaves were collected and dipped in chilled liquid nitrogen and used to isolate DNA applying CTAB method (Hoisington et al., 1994) with own modifications. The $500 \mathrm{mg}$ leaf tissues were ground in liquid $\mathrm{N}_{2}$ and mixed in $5 \mathrm{ml}$ of prewarmed CTAB extraction buffer $(2 \%$ (w/v) CTAB, $20 \mathrm{mM}$ EDTA, $1.4 \mathrm{M} \mathrm{NaCl}, 100 \mathrm{mM}$ Tris- $\mathrm{HCl}$ (pH 8.0) and $0.2 \%(\mathrm{v} / \mathrm{v}) \quad \beta$-mercaptoethanol with $2 \% \mathrm{PVP}(\mathrm{w} / \mathrm{v})$ added immediately prior to use and incubated at $65^{\circ} \mathrm{C}$ for $1 \mathrm{~h}$. The content was mixed with equal volume of chloroform: isoamyl alcohol (24:1) and subjected to centrifugation for $10 \mathrm{~min}$ at $12,000 \mathrm{rpm}$ at $4^{\circ} \mathrm{C}$. Sample was taken out from ultracentrifuge and aqueous phage was pipette out in a $25 \mathrm{ml}$ autoclaved tube. Equal volume of chilled Iso-propanol was added in aqueous phage to precipitate the DNA. Precipitated threads of DNA were pipette out in a $2 \mathrm{ml}$ appendroff tubes using wide bore tip followed by centrifugation at $12,000 \mathrm{rpm}$ for $10 \mathrm{~min}$. Milky white pellet was washed with $70 \%$ alcohol; air dried and re-suspended in $100 \mu \mathrm{l}$ TE buffer (10 mM Tris, 1mM EDTA, pH 8.0). To degrade RNA content RNAse treatment was given for $1 \mathrm{~h}$ at $30^{\circ} \mathrm{C}$. The quality and quantity of the genomic DNA was checked on $0.8 \%$ (w/v) agarose gel and diluted appropriately for working concentration of $25 \mathrm{ng} / \mu \mathrm{l}$.

ISSR marker genotyping: The Polymerase chain reaction was performed in a thermal cycler (MyGene, 96G) using 19 ISSR primers synthesised by Bangalore Genei, India. The PCR was carried out in $25 \mu 1$ reaction volume containing genomic DNA (50 ng), 1.5 mM MgCl2, 1.2 mM dNTPs, $0.7 \mu \mathrm{l}(1 \mathrm{U} / \mu \mathrm{l})$ Taq DNA polymerase and $19 \mathrm{ng}$ primer (Table 2 ). The cycling conditions included initial cycle of denaturation at $94^{\circ}$ $\mathrm{C}$ for $4 \mathrm{~min}$ followed by repeated 35 cycles of denaturation at $94^{\circ} \mathrm{C}$ for $45 \mathrm{~s}$, annealing differ for each primers for $45 \mathrm{~s}$ and extension at $72^{\circ} \mathrm{C}$ for $6 \mathrm{~min}$. After completion of 35 cycles, a final extension at $72^{\circ} \mathrm{C}$ for 5 min was carried out and finally held at $4^{\circ} \mathrm{C}$. The amplified products resulting from different primers were resolved on $2.4 \%(\mathrm{w} / \mathrm{v})$ agarose gel and analyzed by standard ethidium bromide staining and finally photographed using Gel documentation system (Alfa Innotech, USA). The PCR amplification was performed twice with each primers and band scoring was done accordingly.

Statistical analysis: The bands resulting from different sets of ISSR primers for different populations of Saccharum spp. hybrid were scored from agarose gel photograph (Fig. 1). The image profiles of banding patterns were recorded and molecular weight of each bands were determined by DNA ladder. The results were analysed based on the principle that a band is considered to be polymorphic if it is absent in at least one individuals or accessions. Similarity index of bands which were common between two accessions was estimated (Nei and Li, 1979). The ISSR data generated with 19 ISSR primers were used to calculate pair wise similarity coefficients using Jaccard's coefficient of similarity (Jaccard, 1908). The cluster analysis and dendrogram construction were performed with NTSYS-PC (version 2.02e) software for generating phylogenetic tree using the unweighted pair group method with arithmetic average (UPGMA) method (Nie and Li, 1979).

\section{RESULTS AND DISCUSSION}

For ISSR analysis, a total of nineteen primers were used on 14 genotypes of sugarcane for polymerase chain reaction (PCR) amplification (Table 2). The PCR product was electrophoresed on $2.4 \%$ agarose gels (Fig. 1). Bands were counted and the presence and absence of bands were scored as 1 and 0 , respectively. The PCR amplicons sizes ranged from 0.26 to $3.2 \mathrm{~Kb}$. These sets of primers revealed intra-specific variations. A total of 164 bands were scored with 109 polymorphic and 55 monomorphic bands (Table 2). The 14 sugarcane genotypes were clustered based on the matrix of genetic similarities using the Unweighted Pair Group Method with Arithmatic Mean (UPGMA). The cluster analysis and dendrogram construction were performed with NTSYS-PC (version 2.02e). Using 19 ISSR markers, a total of 164 alleles were detected among 14 genotypes studied. The average number of allele per locus was 8.83 . Dendrogram was constructed based on genetic distance calculated from 164 alleles generated from 14 genotypes. The UPGMA cluster tree analysis led to the grouping of genotypes into three major clusters (Fig. 2). Cluster I was the largest one and comprised eight genotypes, cluster II was the smallest and comprised only one genotype while cluster III comprised of five genotypes among selected 14 sugarcane genotypes (Table 4). The PIC value per locus ranged from 0.14 (UBC811) to 0.53 (ISSR1) locus, with an average of 0.42 for all loci (Table 2).

The two-dimensional plot generated from PCoA also supported the clustering pattern of the UPGMA dendrogram (Fig. 3). This reflected a higher genetic diversity in the studied collection, which was confirmed by a principle component analysis of the genotype data. Results of this analysis showed a wider genetic distribution of genotypes in the studied collection. In the three-dimensional PCoA plot, generally, similar groupings with the UPGMA dendrogram and additional information were also revealed. The first three principal axis accounted for the total variation indicating the complex multidimensional nature of ISSR variation (Fig. 4). The range of genetic distance or coefficient of 


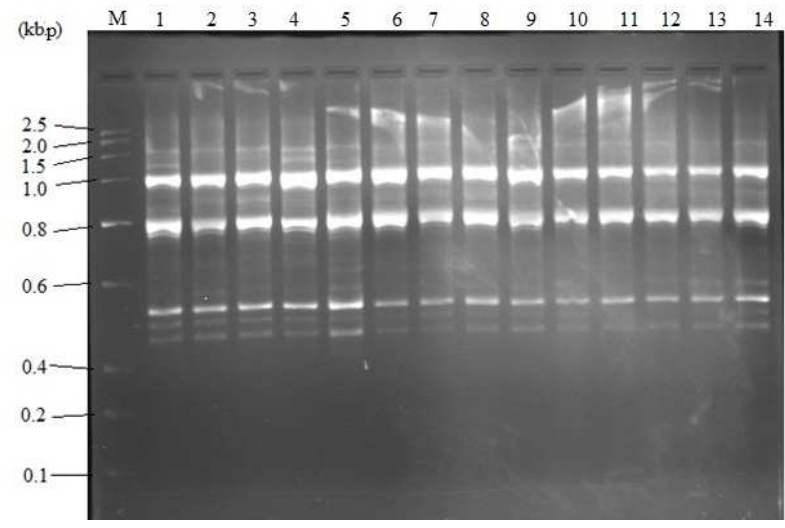

Fig. 1. ISSR amplification of genomic DNAs of Saccharum spp. hybrid used in this study through ISSR primer UBC814 and depicting species specific amplicons (accession numbers 1, 4 and 5). $M$ gene ruler $100 \mathrm{bp}$ DNA ladder, Lane 1. CoS03234, CoSe 01424, Co0118, Co0238, CoC671, CoJ64, Col148, CoS08272, CoS 95255, BO91, UP9530, CoSe1434, UP49 and CoS7250

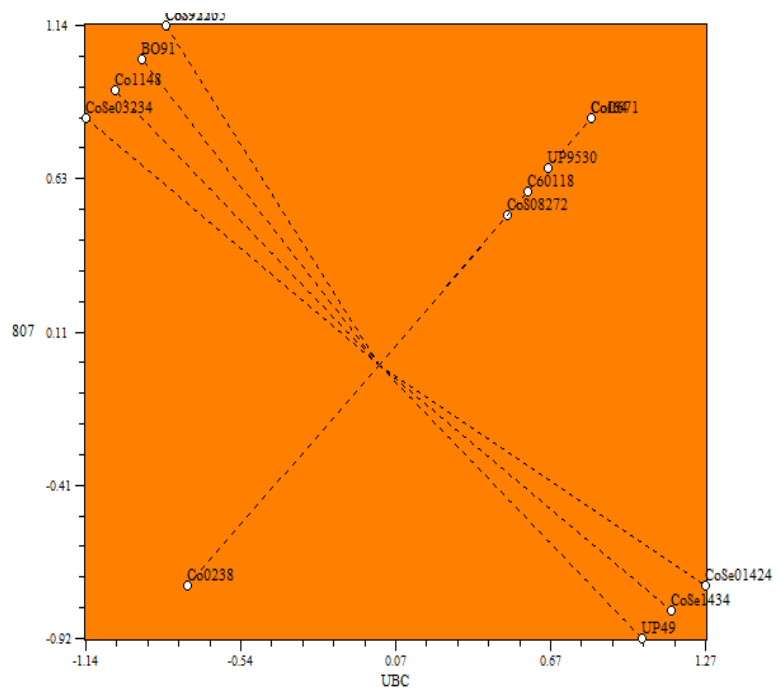

Fig. 3. Two dimensional plot showing relationships among 14 sugarcane accessions using 164 ISSR bands and extracting the first three PCA components.

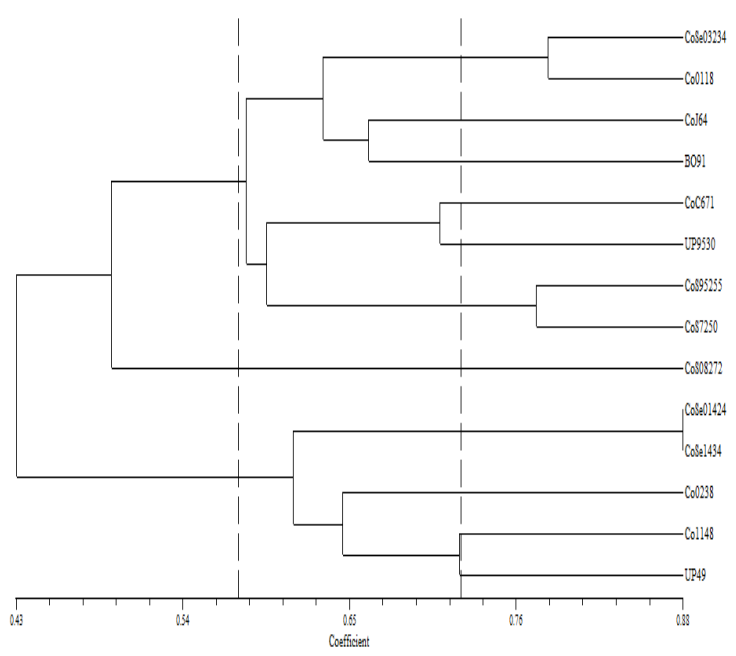

Fig. 2. Dendrogram for 14 sugarcane genotypes showing the genetic similarities derived from UPGMA cluster analysis using the Jaccard similarity coefficient.

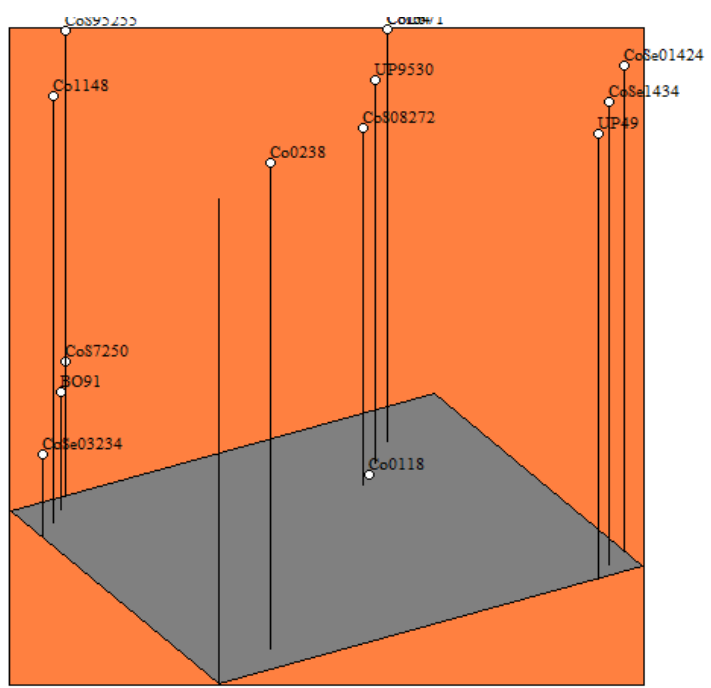

Fig. 4. Three dimensional plot showing relationships among 14 sugarcane accessions using 164 ISSR bands and extracting the first three PCA components.

Table 1. Characteristics of selected fourteen sugarcane genotypes.

\begin{tabular}{|c|c|c|c|}
\hline S.N. & Varieties & Parents & Maturation type \\
\hline 1 & $\operatorname{CoS} 03234$ & Bo 91 X PCGC cross & Early \\
\hline 2 & CoSe 01424 & Bo 91 X Co 453 & Early \\
\hline 3 & Co 0118 & CoS 8347 X Co 86011 & Early \\
\hline 4 & Co 0238 & CoLK 8102 X Co 775 & Early \\
\hline 5 & CoC 671 & Q $63 \times$ Co 775 & Early \\
\hline 6 & CoJ 64 & Co 976 X Co 617 & Early \\
\hline 7 & Co 1148 & P 4383 X Co 191 & Early \\
\hline 8 & CoS 08272 & CoSe 92423 GC cross & Early \\
\hline 9 & CoS 95255 & Co 1158 X Co 62198 & Early \\
\hline 10 & BO 91 & Bo $55 \times$ Bo 43 & Midlate \\
\hline 11 & UP 9530 & CoSe $1084 / 86$ x CoSe $22 / 85$ & Midlate \\
\hline 12 & $\operatorname{CoS} 01434$ & Co 880239 X Co 775 & Midlate \\
\hline 13 & UP 49 & CoSe 92423 X UP 9742 & Midlate \\
\hline 14 & $\operatorname{CoS} 7250$ & CoS 8436 X Co 775 & Midlate \\
\hline
\end{tabular}


Vivekanand P. Rao et al. / J. Appl. \& Nat. Sci. 8 (3): 1404 - 1409 (2016)

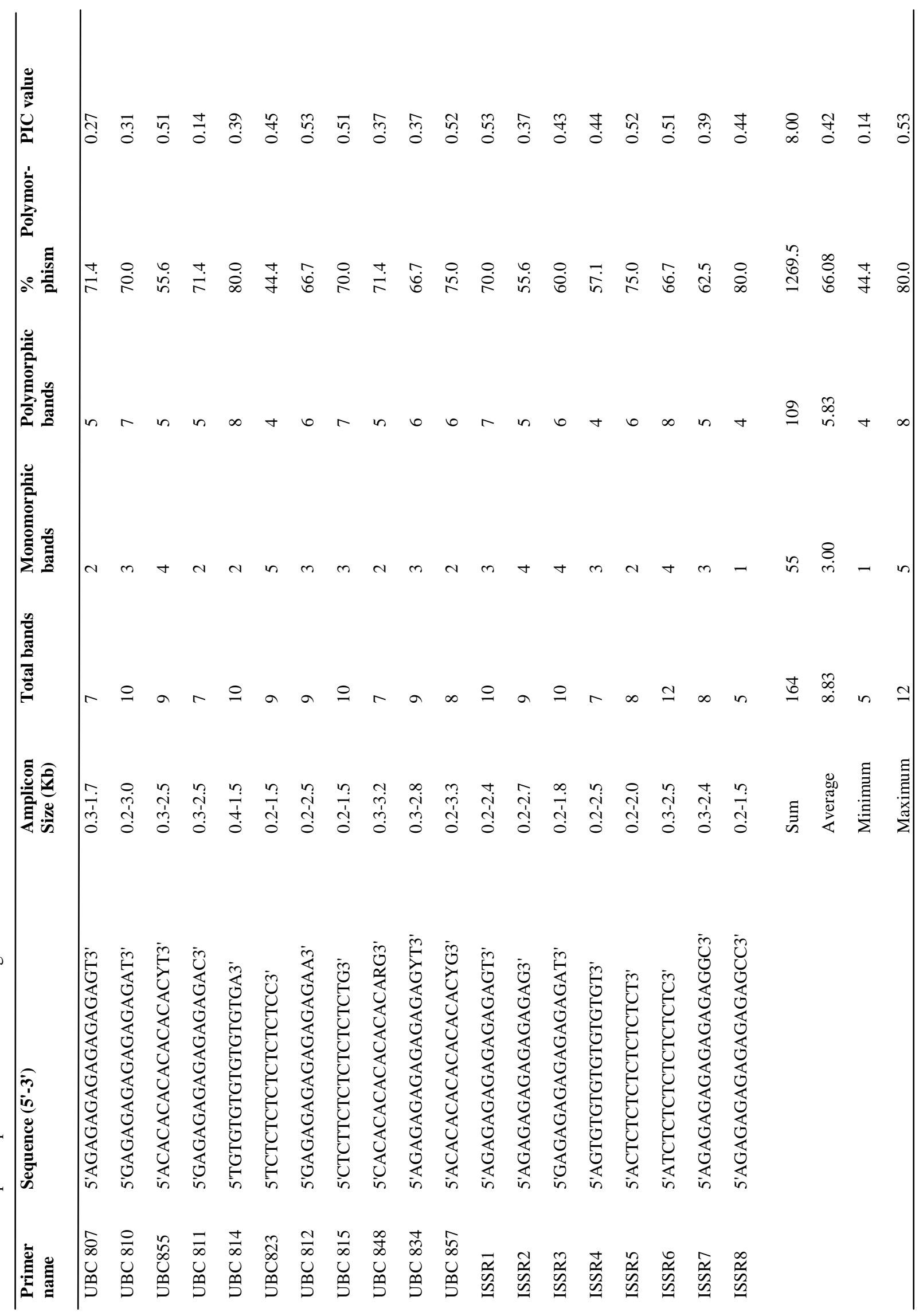


Vivekanand P. Rao et al. / J. Appl. \& Nat. Sci. 8 (3): 1404 - 1409 (2016)

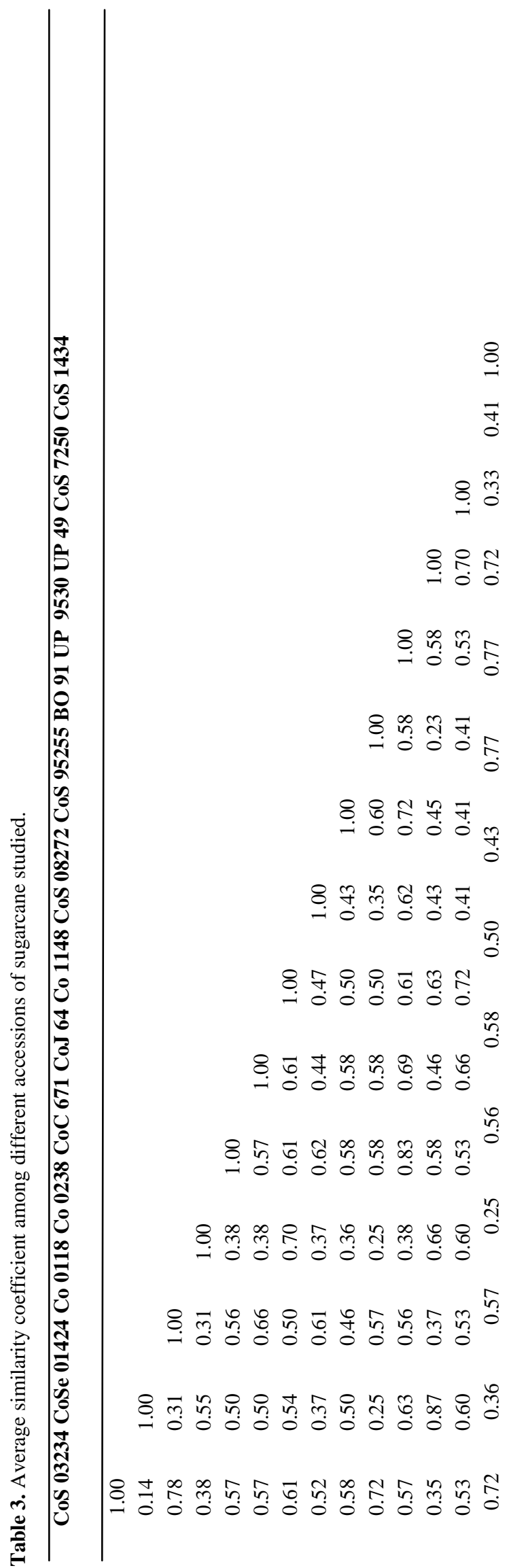

Table 4. Cluster of dendrogram based on ISSR markers in fourteen accession of sugarcane.

\begin{tabular}{|c|c|c|}
\hline Clusters & $\begin{array}{l}\text { Fre- } \\
\text { quency }\end{array}$ & Genotypes \\
\hline Cluster-1 & 8 & $\begin{array}{l}\text { CoS 03234, Co 0118, CoC 671, } \\
\text { CoJ 64, CoS 95255, BO 91, UP } \\
9530, \text { CoS } 7250\end{array}$ \\
\hline Cluster-2 & 1 & $\operatorname{CoS} 08272$ \\
\hline Cluster-3 & 5 & $\begin{array}{l}\text { CoSe 01424, CoS 01434, Co } \\
0238, \text { Co } 1148, \text { UP } 49\end{array}$ \\
\hline
\end{tabular}

similarity among sugarcane genotypes were $0.14-0.78$. The analysis of these similarities matrix revealed that greater similarity between CoSe03234 and CoSe1424 (0.78), and lowest similarity between CoSe03234 and Co0118 (0.14) (Table 3). Those cultivars that display similar coefficient of matrix are genetically close to one another and vice-versa. Using ISSR as genetic markers, as high as $66.08 \%$ polymorphic bands were detected in 14 accessions of sugarcane; similar studies were conducted previously using 37 sugarcane varieties with 8 ISSR primers. A total of 33 bands were amplified, of which $39.4 \%$ were polymorphic. The genetic similarity coefficients amongst 37 sugarcane varieties ranged from 0.67 to 0.97 , with the average of 0.873 , by He et al. (2011). Seventeen sugarcane genotypes were carried out by using 27 ISSR markers. Out of the 252 amplicons amplified by 27 ISSR primers, 212 were polymorphic $(84.13 \%)$ with an average of 9.3 alleles per locus by Kalwade et al. (2012). Eighty one sugarcane genotypes were used to characterize by ISSR primers. A total of 13 ISSR primers used and produced 65 amplified fragments, of which 63 (96.5 $\%)$ were polymorphic. The Polymorphic Information Content (PIC) value ranged from 0.11 (UBC824) to 0.45 (UBC825) primers with an average value of 0.28 by Devarumath et al. (2012) and Costa et al. (2011). High level of polymorphism has been reported in wheat through ISSR markers by Sadigova et al. (2014). The average polymorphism produced by 11 selected ISSR primers performed to estimate genetic diversity among 27 rice varieties was more than $75 \%$ which may be due to wide range of pedigrees of varieties (Al-Turki, 2015). Therefore, the present investigation reported the results of a study on the genetic diversity among 14 accessions of sugarcane revealed by ISSR.

\section{Conclusion}

This study will facilitate in marker-assisted applications in sugarcane breeding. The present investigation is an initial step to evaluate the molecular diversity of this critically complex genome and polyploidy nature of different sugarcane accessions. It would be helpful to conserve sugarcane ex-situ as well identification of parents for breeding improvement programme and also to fulfil the growing demand at national and international market. 


\section{ACKNOWLEDGEMENTS}

Authors are thankful to the Director Seed, Department of Agriculture and Co-operation, Ministry of Agriculture, Govt. of India, New Delhi for financial assistance (No. 2-12/2005/SD-V/6) through project.

\section{REFERENCES}

Al-Turki,T.A. and Basahi M. A. (2015). Assessment of ISSR based molecular genetic diversity of Hassawi rice in Saudi Arabia. Saudi Journal of Biological Sciences. 22 : 591-592.

Costa, M.L., Amorim, L.L.B., Onofre, A.V.C., Melo, L.J.O.T., Oliveira, M.B.M., Carvalho, R. and Iseppon, A.M.B. (2011). Assessment of Genetic Diversity in Contrasting Sugarcane Varieties Using Inter-Simple Sequence Repeat (ISSR) Markers. American Journal of Plant Sciences. 2 : 425-432.

Devarumath, R.M., Kalwade, S.B., Kawar, P.G. and Sushir, K.V. (2012). Assessment of Genetic Diversity in Sugarcane Germplasm Using ISSR and SSR Markers. Sugar Tech. 14 : 334-344.

FAOSTAT. (2015). Statistical Division: Production domainCrops. Updated August 24, 2015; Retrieved on December 21, 2015.

He, W.H., Xu, C.Y., He, L.F., Li, C.Z. and Wei, S.Q. (2011). Assessment of genetic diversity amongst sugarcane varieties from different regions using ISSR markers. Proceeding of $4^{\text {th }}$ IAPSIT, Balancing Sugar and Energy Production in Developing Countries: Sustainable technology and Marketing Strategies, New Delhi, India. pp. 695-700.

Hoisington, D., Khairallah, M. and Gonzalez-de-Leon, D. (1994). Laboratory protocols: CIMMYT applied molecular genetics laboratory, 2nd ed. Mexico. CIMMYT.

Jaccard, P. (1908). Nouvelles recherches sur la distribution florale. Bul. Soc. Vaudoise. Sci. Nat. 44 : 223-270.

Kalwade, S. B., Devarumath, R. M., Kawar, P. G., Sushir, K. V. (2012). Genetic profiling of sugarcane genotypes using Inter Simple Sequence Repeat (ISSR) markers. Electronic Journal of Plant Breeding. 3 : 621-628.

Nei, M. and Li, W. H. (1979). Mathematical model for studying genetic variation in terms of restriction endonucleases. Proc. Natl. Acad. Sci. 76 : 5269-5273.

Pandey, R. N., Singh, J., Rastogi, S. P., Sharma, M. L. and Singh, R. K. (2012). Early assessment of genetic fidelity in sugarcane (Saccharum officinarum) plantlets regenerated through direct organogenesis with ISSR and SSR markers. Australian Journal of Crop Science. 6 : 618-624.

Rao, V. P., Chaudhary, R., Singh, S., Sengar, R. S. and Sharma, V. (2014). Assessment of genetic diversity analysis in contrasting sugarcane varieties using Random Amplified Polymorphic DNA (RAPD) markers. African Journal of Biotechnology. 13 : 3736-3741.

Sadigova, S., Sadigov, H., Eshghi, R., Salayeva, S. and Ojaghi, J. (2014). Application of RAPD and ISSR markers to analyses molecular relationships in Azerbaijan wheat accessions (Triticum aestivum L.). Bulg. J. Agric. Sci. $20: 87-95$.

Singh, S., Gautam, R. K., Singh, R. K., Deshmukh, R. and Ojha, A. (2010). Molecular diversity in rice genotypes differing in physiological mechanism of salt tolerance through SSR and ISSR markers. IJABPT. $1: 550-560$.

Tabasum, S., Khan, F. A., Nawaz, S., Iqbal M. Z. and Saeed, A. (2010). DNA profiling of sugarcane genotypes using randomly amplified polymorphic DNA. Genetics and Molecular Research. 9:471-483

Zhang, H. Y., Li, F. S., Liu, X. Z., He, L. L., Yang, Q. H. and He, S. C. (2008). Analysis of genetic variation in Erianthus arundinacues by Inter simple sequence repeat markers. African Journal of Biotechnology. 7 : 3414-3418. 